\title{
FARMERS' COMPARATIVE USE ASSESSMENT OF WIND AND ELECTRIC PUMP FOR IRRIGATION
}

\author{
Kutsanedzie Felix ${ }^{1}$, Diaba Kwasi Selassie ${ }^{2}$ \\ ${ }^{1}$ Accra Polytechnic, GP 561, Accra-Ghana. \\ ${ }^{2}$ Anglican University College of Technology, Nkorazan, Sunyani-Ghana
}

\begin{abstract}
Keta District provides one of the best wind regimes in Ghana and farming is the main occupation of most people in the communities of the district, notably the anloga community.A small size wind pump (1.6m rotor diameter) is currently in operation in Anloga in the Keta District on pilot bases to verify its cost effectiveness compared with the hydro electric power technology. The high electricity tariff paid every month for power consumption deterred majority of the farmers using hydro electricity technology for pumping. A survey conducted revealed that out of about 50 farmers, only $29 \%$ engaged in the use of electric power for pumping whilst $69 \%$ are still practising the manual method. $2 \%$ of the farmers are practising wind energy technology on pilot bases. Farmers in these coastal communities may have engaged in the use of wind energy for water pumping but for its high initial cost.
\end{abstract}

Keywords: wind, irrigation, electric, rural, development - ****

\section{INTRODUCTION}

Water is a fundamental natural resource of life for mankind and one of the most basic necessities for rural development. The demand for water for domestic purposes and crop irrigation is increasing. As a result, surface water is becoming very scarce worldwide (Argaw et al. 2003). To amend these constraints, groundwater has become an important alternative for crop and domestic water supply. To supply the groundwater for domestic and agricultural use, it has to be pumped and this requires energy. Though the water supply can be done manually, for purposes of commercial farming where substantial amount of water must be supply for irrigation purposes, the manual method may not be efficient and would expose humans to drudgery. The pump type to be used would be dictated by the sources of energy.

According to UNIDO (2008), agricultural mechanization is the application of mechanical technology and increased power to agriculture, largely as a means to enhance the productivity of human labour and often to achieve results well beyond the capacity of human labour. FAO (2008) concluded that one of the major reasons for the disappointing performance and low contribution of mechanization to agricultural development in Africa has been the fragmented approach to mechanization issues. In the 1970s, Asia advanced in prosperity tied to increasing commercialization of agriculture by supporting massive investments in irrigation, fertilizer and high-yielding varieties (the green revolution). This went hand in hand with increasing power inputs, mainly in the form of tractors for land preparation and diesel engines for irrigation (UNIDO 2008). Hossain (2009) reported that Bangladesh food production has increased from 11.0 million tons in 1971 to about 30 million tons in 2007. The country is, at present, about to achieve self-sufficiency in cereal production. This is due to irrigation development and partial mechanization in other agricultural operations. However MoFA (2007) characterizes the agricultural sector in Ghana as predominantly practised on smallholder, family-operated farms using rudimentary technology to produce about 80 percent of Ghana's total agricultural output.

Currently bulk of the country's energy needs is supplied via hydro electric power and thermal electric power. However with the energy crisis plaguing the country, there other renewable energy sources which are environmentally friendly. Windmills for water pumping can be a solution for long-term, environmental friendly ways of water pumping. The short name of "a windmill for pumping water" is called "wind pump" (Matsen et al 2004). According to Kristoferson and Bokalders (1991) windmills were used throughout Northern Europe not only for water pumping, grinding grains and for a variety of other uses. Wind turbines with a total generating capacity of over 9500 megawatts had been built around the world and they generated enough power for about 3.5 million homes (FAE 1991).

Wind pumps and electric pumps are now emerging from the market and are rapidly becoming more attractive to farmers compared to the named traditional power sources which are rather more expensive for local farmers more. Thus the rationing of electricity power in the country as a result of insufficient power generation makes it availability unreliable for irrigation of crops.

This paper aims at studying farmers comparative assessment of the use of electric and wind in the supply of water for agricultural purposes in the Anloga community in Keta District of the Volta Region. 


\subsection{Research Area Description}

The people of the Keta District are called the Anlos. The district falls within the dry equatorial climate with an annual average rainfall of about $1,000 \mathrm{~mm}$ (MoFA 2006). The amount of rainfall reduces from $1,000 \mathrm{~mm}$ as one travels from the north to the coastal belt where only about $800 \mathrm{~mm}$ annual rainfall may be recorded (MoFA 2006).

Geographically, Keta District is located in the southern sector of the Volta Region of Ghana. The District lies within longitude $0.30 \mathrm{E}$ and $1.050 \mathrm{E}$ and latitude $5.450 \mathrm{~N}$ and $6.0050 \mathrm{~N}$. It is sandwiched between two major surface water bodies - the Keta lagoon and the Gulf of Guinea. It is a flat land full of sandy soil owing to its proximity to the Keta beach.

The indigenous Anlo communities basically engage in vegetable production and salt winning on commercial scale since time immemorial. They mainly produce shallot, pepper, tomato and okro. More often than not, some of these farmers cultivate other crops such as corn, cassava and coconut on subsistence bases.

Wells are drilled to a depth of about 1-9m to provide water for irrigation. Buckets and / or watering cans are used to draw water manually from the wells. These buckets of water are sprinkled manually on the vegetable beds two times a day (morning and evening) as a form of irrigation. Where pumps are used, rubber hoses are used for irrigation. In this case pressure is exerted on the open end of the hose with the fingers by way of apparently reducing the diameter. This action mimics rainfall or sprinkler discharges.

\subsection{Problem Statement}

Although the sprinkler irrigation system seemed to be gaining ground as some farmers are embracing it, the higher cost of electric power consumption and power rationing affects power supply for pumping of water. The need for other lesser cost and more stable power sources such as wind energy becomes imminent.

\subsection{Objective of the study}

The prime objective of this research is to assess how farmers compare the use of electric and wind pumping systems of irrigation on their farmers as regard the cost involved in the use of the respective systems in order to make their appropriate recommendations

\section{MATERIALS AND METHODS}

A well structured questionnaire was administered to farmers to solicit their responses on the two systems (electricity and wind power) for pumping water on their farms. The questionnaire captured questions on the farming systems practised, vegetables cultivated, sizes of farms per season, length involved in farming, cost invested into farming, total irrigation period per farming season, types of pump and number used per farm size, the cost incurred in operating the pump as well as other affecting factors associated with the irrigation systems adopted.

A purposive sampling technique was adopted because not all farmers use both systems and hence some are unable to do a comparative assessment and evaluation of both systems.

\section{RESULTS AND DISCUSSION}

The 48 out of 50 administered questionnaires were responded to, and the responses coded and entered into the Statistical Package for Social Scientist (SPSS) version 16 for analysis. The data was summarized using descriptive statistics such as tables and graph and presented discussed below:

\subsection{Age of Farmers}

21-35 years is the average age of most vegetable farmers in the community. This is shown in Figure 9.

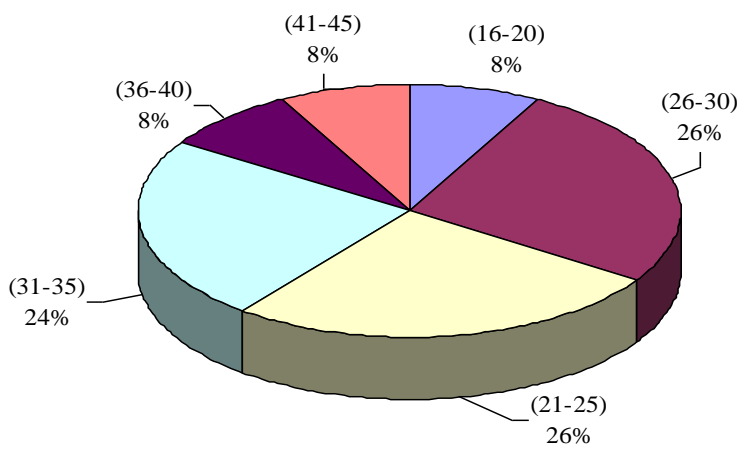

Fig 1: Age group of vegetable farmers

These were youthful, majority of whom belonged to the cooperative society and were engaged mainly in vegetable production on medium to large scale. They were virtually school drop outs with no technical skills. The variations in the educational level of the farmers are shown in figure 2.

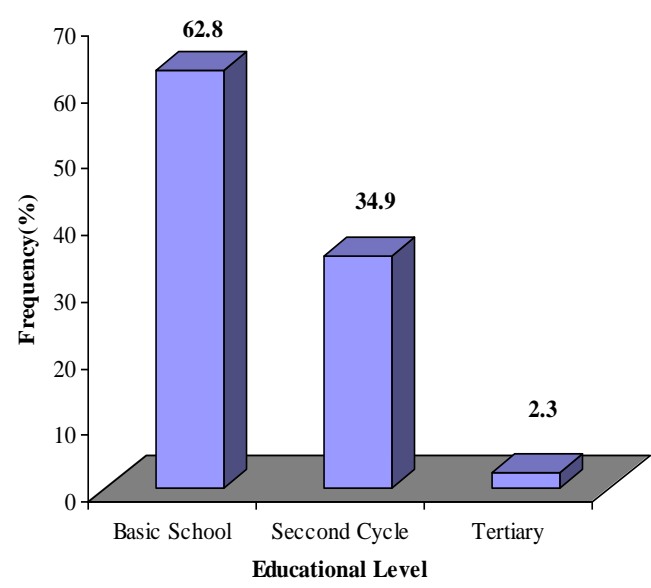

Fig 2: Educational levels of the vegetable farmers 
On the average the highest educational attainment of most of these local farmers was middle or junior secondary school. A majority of $62.8 \%$ constituted the basic school level while only $2.3 \%$ of the farmers attained tertiary level of education.

\subsection{Types of Vegetable Cultivated}

With respect to the type of crop cultivated and when cultivated, Table 1 shows the seasons for each crop.

Table1: Vegetable growing period at Anloga vegetable farming community

\begin{tabular}{|l|l|}
\hline Crop & Period of Cultivation \\
\hline Okro & April-June \\
\hline Pepper & April-July \\
\hline Tomato & July-October \\
\hline Shallot & $\begin{array}{l}\text { January-February; April-June; } \\
\text { August October }\end{array}$ \\
\hline
\end{tabular}

The most common types of vegetable produced by these farmers were shallot, okro, tomato and pepper. The farmers cultivated these types of vegetable because they provided them with good yields. More so some farmers emphasised that these types of vegetable grew well in the soil series there.

\subsection{Type of Irrigation System Practised}

Out of 48 respondents gathered from the administered questionnaires, 15 farmers were found to have engaged in the modern sprinkler irrigation farming system. It was noticed that these farmers acquired land sizes ranging from 0.4 ha to about a maximum of 8 ha. The remaining thirty three (33) respondents comprise farmers with farm sizes ranging from $8 \times 10^{-4}$ to 0.4 ha. These farmers could not afford to practice the modern sprinkler irrigation farming system. They instead use rubber hoses or buckets and watering cans to water their crops.

\subsection{Duration of Practice of the Adopted Irrigation}

\section{System and Pump Type Used}

The average number of years since the practice of sprinkler irrigation farming by a farmer is 5 years. The water pumps used are generally centrifugal pumps which have a suction head of $23 \mathrm{~m}$. These pumps are installed to pump water from boreholes about $9 \mathrm{~m}$ deep using electric power. Most of these farmers have their farms well connected to the national grid.

\subsection{Farm Size}

Whilst some farmers cultivate about 0.8 ha of farm land, on the high side others cultivated about 8 ha. It is estimated that about 2.74 million households operate a farm or keep livestock. About 90 percent of farm holdings are less than 2 ha in size (FAO 2010).

\subsection{Variation of the Sources of Power for Irrigation}

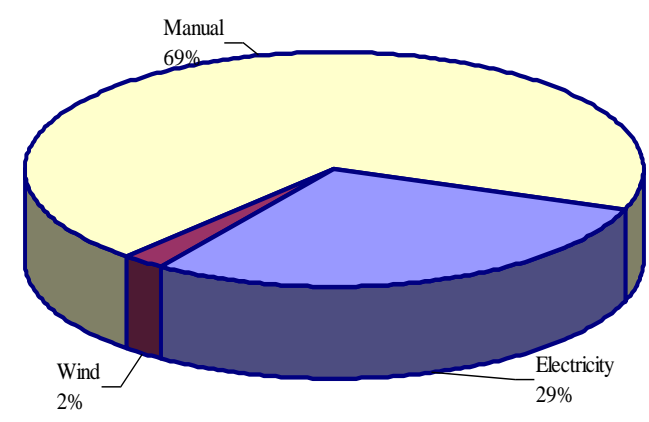

Fig 3: Number of farmers and source of power for water application

From figure 3 about $69 \%$ of the farmers neither depend on electricity nor wind as a source of power/energy for pumping water from the well. They instead, use buckets/watering cans (manual system) to supply water to the crops. $29 \%$ of them used centrifugal electric pump for drawing water from boreholes. Only $2 \%$ of the farmers have engaged in the use of wind pump.

Before the introduction of the modern sprinkler irrigation farming system, a sizeable number of farmers practice the manual bucket watering. Figure 4 shows the farm sizes in hectares used under the three farming practices.

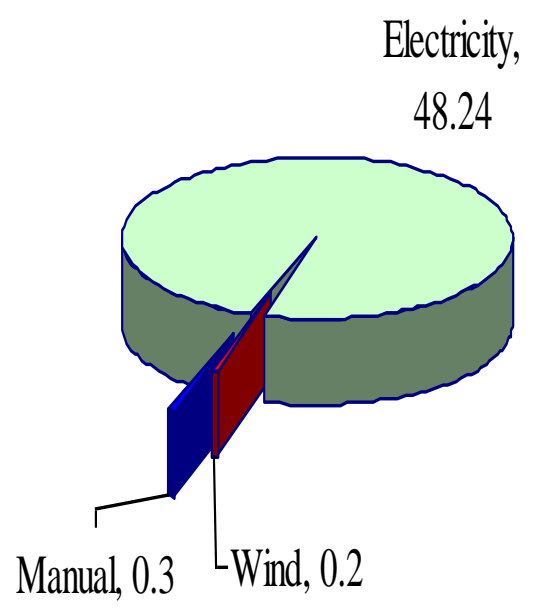

Fig 4: Farm size in hectare and sources of power for water application

\subsection{Cost Analysis}

The graph below indicates ten randomly selected farmers with total investment cost/expenditure against the corresponding farm size. 
Table 2: Total Investment Cost per Farm Size

\begin{tabular}{|l|l|}
\hline Farm Size (ha) & $\begin{array}{l}\text { Total Investment Cost } \\
\text { Farmer }(\mathbf{1} \text { 102) }\end{array}$ \\
\hline $\mathbf{1 . 2}$ & 1.9 \\
\hline $\mathbf{2 . 4}$ & 1.5 \\
\hline $\mathbf{3 . 2}$ & 2.1 \\
\hline $\mathbf{3 . 2}$ & 3.68 \\
\hline $\mathbf{3 . 2 2}$ & 13.3 \\
\hline $\mathbf{4}$ & 12 \\
\hline $\mathbf{4}$ & 1.2 \\
\hline $\mathbf{4 . 4}$ & 9.9 \\
\hline $\mathbf{4 . 8}$ & 11.25 \\
\hline $\mathbf{8}$ & 36 \\
\hline
\end{tabular}

\section{CONCLUSION}

Many people in the Keta District vegetable farming communities wish to farm using the current irrigation farming technology. This notion is often inhibited by economic constrains. Many cannot afford the pumps and other irrigation materials. About $69 \%$ of local farmers continued to depend on manual water application system for their agriculture. For economic and agronomic reasons, the system of irrigation which reduces strain on the part of farmers and moreover, boosts the income generation of both the farmers and the manufacturers of the irrigation materials is the wind powered technology. This technology is also environmentally friendly.

\section{ACKNOWLEDGEMENTS}

The authors would like to acknowledge all lecturers of Agricultural Engineering Department of KNUST in Ghana for their guidance and diverse contributions to this paper.

\section{REFERENCES}

[1]. Argaw, N., Foster, R. and Ellis, A. Renewable Energy for Water Pumping Applications in Rural Villages. NREL/SR-500-30361, New Mexico State University: Las Cruces, New Mexico, 2010. Available at: http://www.osti .gov /bridge (accessed 4 August 2006)

[2]. Foundation for Alternative Energy (FAE).Wind Energy, Slovak non-governmental organisation committed to environmental protection, 1995. Available at: http://www.seps.sk/zp/fond/profile.html (accessed12 February 2007).

[3]. FAO. Agricultural and Food Engineering Technical Report: Agricultural mechanization in Mali and Ghana: strategies, experiences and lessons for sustained impacts, 2010. Available at:http://www.fao. org/ag/ags ( accessed 10 October 2013)

[4]. Kristoferson, L.A., Bokalders, V. Renewable energy technologies Intermediate Technology publications, 103/105 Southampton Row, WC1B 4HH, UK.,1991.

[5]. Matsen Jorritsma and Koen van Noorden. Sustainable implementation of wind pump projects in TASAF supported villages. MSc. Thesis, Technological Development Studies (TDS), Department of Technology Management (TM),
Eindhoven University of Technology (TU/e), the Netherlands, 2004.

[6]. Ministry of Food and Agriculture, MoFA. Report on Survey of Informal Irrigation Farms in the Keta District of the Volta Region, MoFA, Anloga, Ghana, 2006.

[7]. FAO. Agricultural Mechanization in sub-Saharan Africa: Time for a New Look. Rome: Food and Agriculture Organization of the United Nations, Occasional paper, 2008. [8]. Hossain, M.S. Food Security Situation in Bangladesh with Focus on the Impact of High Food Prices. The Guardian. A national Monthly, published by editor from 794/KA, South Shajahanpur, Dhaka-1217, Bangladesh, 2009.

[9]. MoFA. Food and Agriculture Sector Development Policy (FASDEP II). Accra-Ghana: MoFA., 2007. 70 pp.

[10] UNIDO. Agricultural mechanization in Africa: Planning investment for enhanced agricultural productivity Report of an Expert Group Meeting January 2008, Vienna, Austria, 2008. 